\title{
Monte Carlo Simulation for Slope Stabilization Using Drilled Shafts
}

\author{
Lin $\mathrm{Li}$ \\ Geotechnical Engineering Group, URS Corporation, Cleveland 44115, USA
}

\begin{abstract}
A reliability based analysis method for a drilled shaft stabilized slope system is presented in this paper. The drilled shaft stabilization mechanisms for the slope were treated as the drilled shaft induced soil arching, which was quantified by the load transfer factor in the limited equilibrium analysis. However, due to the inherent uncertainties of the soil properties and the model error of the semi-empirical load transfer equation, an extension modification of the deterministic method into a probabilistic method is developed in this paper. The MCS (Monte Carlo simulation) with log-normal random variables has been employed to calculate the probability of failure $\left(P_{f}\right)$ for the drilled shafts/slope system. The developed theories were coded into a computer program for analyzing complex slope geometry and slope profile conditions. Finally, a case study has been performed to illustrate the application analysis of the developed probability approach in drilled shafts/slope system.
\end{abstract}

Key words: Monte Carlo, drilled shafts, slope stability, arching.

\section{Introduction}

Along the highways, landslides and slope failures occur frequently every year which have major impact on the operational safety of roadways and add financial burden to the highway agencies for slope repairs and maintenance. Analysis of drilled shafts stabilizing slope systems has been a research topic since 1980s.In general, the analysis methodologies could be categorized into two approaches: increase in the resistance due to the added shear strength of the reinforced concrete drilled shafts [1] and decrease in the driving force due to the soil arching as a result of the inclusion of rigid structural elements. The later approach was pioneered by Liang and his associates [2-17]. To interpret the interaction between drilled shafts and the slope, soil arching theory was proposed and developed.

Currently, the most common methodology for current slope stability analysis is the LEM (limit equilibrium method) and FEM (finite element method). The uncertainties mentioned in the problem

Corresponding author: $\mathrm{Lin} \mathrm{Li}$, Ph.D., research field: geotechnical engineering. E-mail: lin.li@urs.com. are addressed collectively by imposing a required factor of safety, such as a factor of safety of 1.2 for temporary slopes and 1.5 for permanent slopes. Nevertheless, the prescribed factors of safety do not change regardless of the degree of variability and/or uncertainties in the problem. Furthermore, a drilled shafts/slope system designed with a nominal safety factor of more than 1 is not necessarily safe because of underlying geotechnical variability and inherent uncertainties in the computational methods.

Probability based approach for slope stability analysis has been a subject of research since 1970s [18, 19]. However, reliability analysis on drilled shafts stabilizing slope needs to be developed from deterministic methodology to probabilistic method to account for inherent uncertainties in soil properties, slope failure mechanisms and spatial variations of soil properties.

\section{Deterministic Analysis for Drilled Shaft/Slope System Using Soil Arching Theory}

Piles or drilled shaft stabilizing slope has been analyzed by numerous researchers since 1960s. Using drilled shafts for stabilizing slopes can be a viable technique, however, there is still not a universal 
accepted design method and the accepted factor of safety for the shaft/slope system. During the past years, the deterministic analysis methodologies for the drilled shafts/slope system have also transitioned from the concept of "increased resistance" (Eq. (1)) to the concept of "decreased driving force" (Eq. (2)):

$$
\begin{aligned}
& F S=\frac{F_{R}+\left(\Delta F_{R}\right)_{\text {shaft }}}{F_{D}} \\
& F S=\frac{F_{R}}{F_{D}-\left(\Delta F_{D}\right)_{\text {arching }}}
\end{aligned}
$$

where, $F S$ is the global factor of safety for the slope/shaft system, $F_{R}$ is the resistance force, $\left(\Delta F_{R}\right)_{\text {shaft }}$ is the additional resistance from the drilled shafts, $F_{D}$ is driving force, $\left(\Delta F_{D}\right)_{\text {arching }}$ is drilled shaft induced arching effect on the driving force.

\subsection{Load Transfer Factor}

To interpret arching theory in drilled shafts/slope system, the load transfer factor is introduced and defined as the ratio between the down-slope side force and the up-slope side force, which are at the interface between the drilled shaft and soil. Mathematically, the load transfer factor is expressed as:

$$
\eta=P_{\text {down-slope }} / P_{\text {up-slope }}
$$

where, $P_{\text {up-slope }}$ is the resultant horizontal force on the vertical plane at the interface between the drilled shaft and soil on the up slope side. $P_{\text {down-slope }}$ is the resultant horizontal force on the down-slope side of the vertical plane at the interface between the drilled shaft and soil.

Joorabchi [7] used 41 finite element models to modify the semi-empirical equation and the obtained equation is highly related with six parameters: soil cohesion $c$, friction angle $\varphi$, shafts diameter $D$, shafts spacing $S$, shafts location $\xi_{x}$ and slope angle $\beta$. The load transfer factor function is shown in the following equation:

$$
\begin{aligned}
& \eta=-0.272 C^{0.153}(\tan \beta)^{-0.429}\left(-1.17+1.114 \frac{S}{D}\right) \\
& \left(\mathrm{e}^{-0.578 \tan \varphi}\right)(0.065+0.876 D)\left(-0.252+0.61 \xi_{x}\right. \\
& \left.-0.57 \xi_{x}{ }^{2}\right)
\end{aligned}
$$

\section{Uncertainties on Drilled Shafts Stabilizing Slope System}

\subsection{Uncertain Parameters on Shafts/Slope System}

The influencing whole parameters in the drilled shafts/slope system can be divided into expressed as two major categories parts: soil properties (cohesion $c$, friction angle $\varphi$ and unit weight $\gamma$ ) and drilled shaft related parameters pile (shaft diameter $D$, clear spacing $S$ between the adjacent drilled shafts and the location of the shaft on the slope $\xi_{x}$ ). In this paper, the drilled shaft related parameters have been considered as certain while certain value comparing with the soil properties are considered uncertain parameters because of the controllable construction on drilled shafts, i.e., the three soil parameters (cohesion $c$, friction angle $\varphi$ and unit weight $\gamma$ ) will be considered as uncertain during the reliability analysis on drilled shafts stabilizing slope, applying alog-normal distribution. The random generator method will follow the ziggurat algorithm, an algorithm for pseudo-random number sampling based on the accept-reject algorithm, which is currently the most effective algorithm in pseudo-random number generator.

\subsection{Bias of Load Transfer Factor}

The $\eta$ function has been proposed by Liang and Zeng [2] and then analyzed by Yamin [6], finally modified by Joorabchi [7], shown in Eq. (3). This paper will analyze the bias of load transfer factor based on $\eta$ function [7].

The semi-empirical load transfer factor $\eta$ function of Ref. [7] has been obtained based on 41 finite element regression analyses. Obviously, there is a bias $\delta$ between the semi-empirical equation (Eq. (3)) and the real value (result of finite element). Meanwhile, in Eq. (3), the semi-empirical $\eta$ equation is a function of the six parameters: soil cohesion $c$, soil friction angle $\varphi$, slope angle $\beta$, shaft diameter $D$, shaft location $\xi_{x}$ and shafts spacing $S$. There are two uncertain 
soil cohesion $c$ and soil friction angle $\varphi$ which will also be considered as variety. Therefore, the relation between the semi-empirical value and the real value would be the following expression:

$$
\hat{\eta}=\hat{\delta} \eta=\hat{\delta} \eta\left(\hat{c}, \hat{\varphi}, \beta, D, \xi_{x}, S\right)
$$

where, $\hat{\eta}$ is the computed load transfer factor, $\hat{\delta}$ is the bias of the computed load transfer factor, $\hat{c}$ is the random soil cohesion, $\hat{\varphi}$ is the random soil friction angle, $\beta, D, \xi_{x}$ and $S$ have been defined in the above discussion.

\section{Probabilistic Design}

After setting up the uncertainties of soil parameters and the bias of load transfer factor, the loop-calculating will be performed to calculate the probability of failure $\left(P_{f}\right)$. Specific $\mathrm{C}++$ coding has been written based on the deterministic drilled shafts/slope system using the arching theory.

\subsection{Performance Function for the Shaft/Slope System}

According to the factor of safety for drilled shafts/slope system proposed by Liang and Zeng [2], the performance function can be described as the following:

$$
\begin{aligned}
g\left(x_{1}, x_{2}, \cdots x_{n}\right)= & F S-1=\frac{F_{R}}{F_{D}-\left(\Delta F_{D}\right)_{\text {arching }}}-1 \\
& =\frac{F_{R}-F_{D}+\left(\Delta F_{D}\right)_{\text {arching }}}{F_{D}-\left(\Delta F_{D}\right)_{\text {arching }}}
\end{aligned}
$$

\subsection{Monte-Carlo Simulation}

After sampling varieties of soil parameters and bias of load transfer factor, the factor of safety will be calculated each time, and then the indicator function can be obtained subsequently. The probability of failure of drilled shafts/slope system will be described in the following, based on the indicator function:

$$
\begin{aligned}
& \hat{P}_{f}=E(I[x]) \cong \frac{1}{N} \sum_{i=1}^{N} I[F S<1]= \\
& \frac{1}{N} \sum_{i=1}^{N} I_{i}\left(\frac{F_{R}-F_{D}+\left(\Delta F_{D}\right)_{\text {arching }}}{F_{D}-\left(\Delta F_{D}\right)_{\text {arching }}}<0\right) \\
& \delta\left(\hat{P}_{f}\right)=\sigma_{P f} / \mu_{P f} \approx \\
& \sqrt{\frac{1}{N} \sum_{i=1}^{N}\left(I_{i}\left(\frac{F_{R}-F_{D}+\left(\Delta F_{D}\right)_{\text {arching }}}{F_{D}-\left(\Delta F_{D}\right)_{\text {arching }}}<0\right)-\hat{P}_{f}\right)^{2}} / \hat{P}_{f}
\end{aligned}
$$

where, $P_{f}$ is the probability of failure for the drilled shafts/slope system, $\delta\left(\hat{P}_{f}\right)$ is the c.o.v. (coefficient of variation) of $P_{f}, I(F S<1)$ is the indicator function, $N$ is the sample numbers, $\hat{P}_{f}$ is the estimated probability of failure.

\section{Case Study}

In practical cases, the drilled shafts would be installed after the critical sliding surface of the slope has already formed and established by monitoring. In the analysis, the slope has been assumed as one critical slip surface. A baseline model has illustrated the above theory and algorithm, which is stabilized by $1.2 \mathrm{~m}$ in diameter and $2.4 \mathrm{~m}$ clear spacing drilled shafts. The slope shown in Fig. 1 was considered by Joorabchi [7] as an example of "UAS1OPE2.1" program, which can calculate the factor of safety for a slope with/without stabilizing by drilled shafts. The critical slip surface

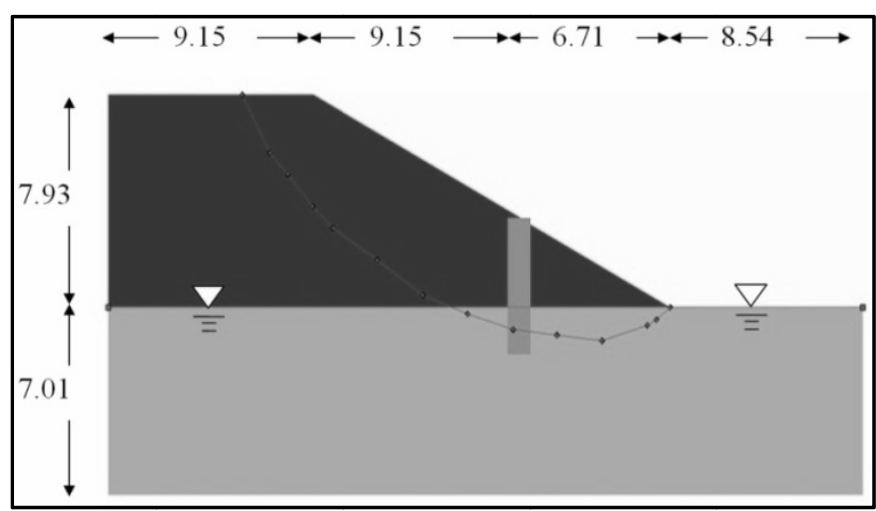

Fig. 1 Slope geometry for baseline model (unit: $\mathbf{m}$ ). 
Table 1 Baseline properties of Example 1.

\begin{tabular}{lllll}
\hline & \multicolumn{2}{c}{ Mean } & & \multicolumn{2}{c}{ c.o.v. } \\
\cline { 2 - 3 } & Layer 1 & Layer 2 & Baseline & Range \\
\hline$C\left(\mathrm{kN} / \mathrm{m}^{2}\right)$ & 0.958 & 2.394 & 0.2 & $0.20-0.45$ \\
Fai & 11 & 18 & 0.1 & $0.1-0.2$ \\
Gamma $\left(\mathrm{kN} / \mathrm{m}^{3}\right)$ & 21.21 & 22.78 & 0.01 & $0.01-0.11$ \\
Drilled shafts & $N_{\eta}=1.01$ & & 0.15 & $0.1-0.2$ \\
Water table & $D=1.2 \mathrm{~m}, S=2.4 \mathrm{~m}$ & & \\
\hline
\end{tabular}

has been formed by 14 monitor points. The groundwater level is on the second soil layer $(-7.93 \mathrm{~m})$ and effective stress approach is used in this study. The drilled shafts are located in $9.15 \mathrm{~m}$ horizontally measured from the top of slope.

The baseline parameters are shown in Table 1. The critical factor of safety for baseline model are 0.788 and 1.219 for without drilled shafts and with drilled shafts, respectively. The range of the c.o.v. shown in Table 1 is adopted by Phoon and Kulhawy [20]. The c.o.v. of each layer is assumed the same and the two layers are following i.i.d. (independent identical distribution).

In this paper, 30,000 samples for each cohesion $C$, friction angle $\varphi$ and unit weight $\gamma$ have been generated by log-normal distribution for baseline model. The two curves of $P_{f}$ (with and without drilled shafts) based on different number of samples have been shown in Fig. 2. The final $P_{f}$ and c.o.v. of $P_{f}$ are $99.86 \%, 0.0003$ and 3.81\%, 0.0873, respectively. Obviously, drilled shafts have significantly improved the slope stability.

Although Joorabchi [7] derived the value of $\eta$ (load transfer factor) which is also uncertain, based on 41 models, specific $P_{f}$ has been analyzed based on different $\eta$ bias means and $S D$ (standard deviation) using log-normal distribution. Fig. 3 shows that the $P_{f}$ will increase when the mean value of $\eta$ bias increases, which means that more load transfer from up-slope to down-slope, more possible failure. Fig. 3 also shows the variety of $\eta$ increasing will lead to the $P_{f}$ increase.

Drilled shaft size is the most important factor for slope stabilizing, four different diameters $(D)$ and three different clear spacing $(S)$ of drilled shafts have been generated in Fig. 4. As shown in Fig. 4, although the increase of $D$ will decrease the $P_{f}$, however, the clear spacing of drilled shafts $(S)$ significantly affect the $P_{f}$

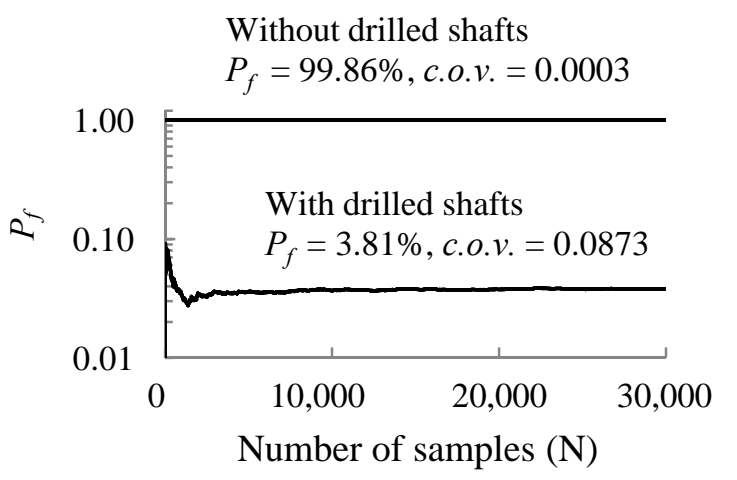

Fig. 2 Convergence of $\boldsymbol{P}_{f}$, with and without drilled shafts.

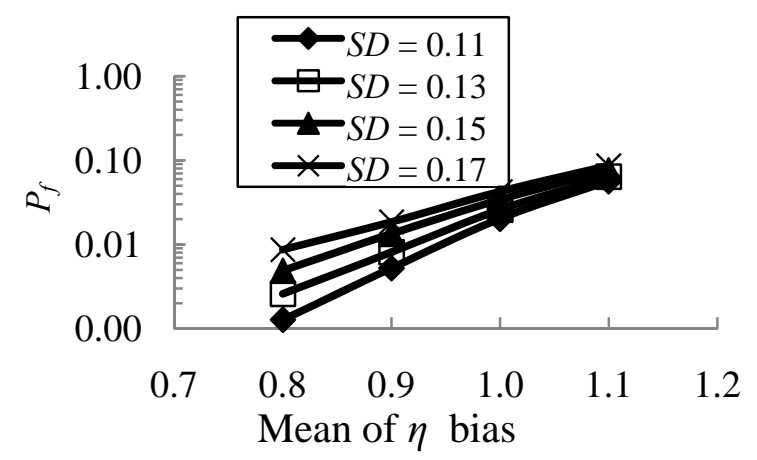

Fig. 3 Relationship between $P_{f}$ and bias $\eta$.

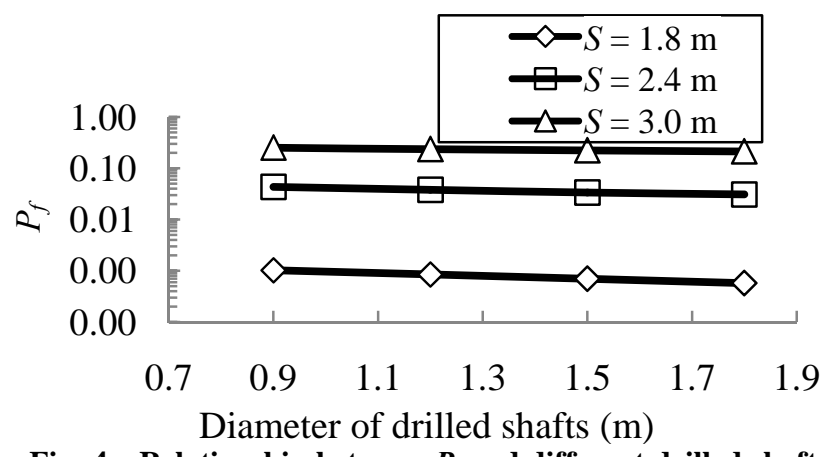

Fig. 4 Relationship between $P_{f}$ and different drilled shafts size. 


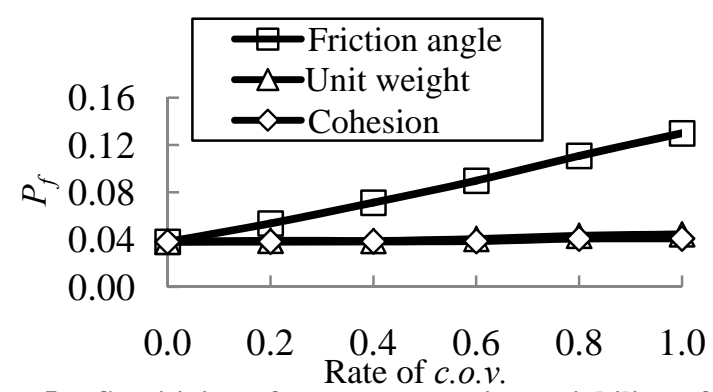

Fig. 5 Sensitivity of $P_{f}$ to uncertain variability of soil properties.

more. The sensitivity results of $P_{f}$ to the variation of soil properties have been shown in Fig. 5, which are also following log-normal distribution and 30,000 samples for each property on Monte Carlo simulation.

As shown in Fig. 5, friction angle $\varphi$ is the most important influence factor in drilled shafts-slope system. The most possible reason would be: when the slope without drilled shafts stabilizing, slope stable is most dependent on shear stress inside soil, i.e., $C$ and $\varphi$; after adding drilled shafts, the driving force has transferred from soil to drilled shafts, arching effect is more and more important than shear stress inside soil to stabilize slope.

\section{Summary and Conclusions}

A new algorithm based on MCS (Monte Carlo simulation) technique for drilled shafts stabilizing slope has been proposed to efficiently estimate the probability of failure for the more generalized slope with underground water. The c.o.v. results provide unbiased and accurate estimates for probability of failure. The results show that the load transfer factor $\eta$ is a very important influence factor in drilled shafts/slope system, which needs further detailed analyzing. In drilled shafts/slope system, friction angle is the most important factor than cohesion and unit weight.

\section{References}

[1] T. Ito, T. Matsui, P.W. Hong, Design method for stabilizing piles against landslide-One row of piles, Soils and Foundations 21 (1) (1981) 21-37.

[2] R.Y. Liang, S. Zeng, Numerical study of soil arching mechanism in drilled shafts for slope stabilization, Soil and Foundations 42 (2) (2002) 83-92.

[3] L. Li, R.Y. Liang, Reliability-based design for slopes reinforced with a row of drilled shafts, International Journal for Numerical and Analytical Methods in Geomechanics 38 (2) (2014) 202-220.

[4] L. Li, R. Liang, Reliability-based optimization design for drilled shafts/slope system, The Journal of the Deep Foundations Institute 6 (2) (2012) 48-56.

[5] X. Jiang, L. Li, J. Yuan, J. Yin, Dynamic analysis of strata horizontal displacements induced by shield construction of deep tunnel, Rock and Soil Mechanics 32 (4) (2011) 1186-1192.

[6] M.M. Yamin, Landslide stabilization using a single row of rock-socketed drilled shafts and analysis of laterally loaded shafts using shaft deflection data, Ph.D. Dissertation, University of Akron, Ohio, 2007.

[7] A.E. Joorabchi, Landslide stabilization using drilled shaft in static and dynamic condition, Ph.D. Dissertation, The University of Akron, Ohio, 2011.

[8] L. Li, X. Jiang, R. Liang, A numerical case study of soil-pile-shield tunneling interaction for Guangzhou subway project, in: GeoFlorida 2010, Florida, USA, 2010, pp. 1737-1746.

[9] R.Y. Liang, A.E. Joorabchi, L. Li, Analysis and design method for slope stabilization using a row of drilled shafts, Journal of Geotechnical and Geoenvironmental Engineering 140 (5) (2014) 1-12.

[10] R.Y. Liang, L. Li, Probabilistic Analysis Algorithm for UA Slope Software Program, Report for Ohio Department of Transportation, 2013.

[11] R.Y. Liang, L. Li, Reliability based design for drilled shafts for slope stabilization, in: Geo-Congress 2013, USA, 2013, pp. 1997-2006.

[12] E. Joorabchi, R.Y. Liang, L. Li, Yield acceleration of a slope reinforced with a row of drilled shafts, in: Geo-Congress 2013, USA, 2013, pp. 1987-1996.

[13] R.Y. Liang, A.E. Joorabchi, L. Li, Design method for drilled shaft stabilization of unstable slopes, in: Geo-Congress 2013, USA, 2013, pp. 2017-2026.

[14] E. Joorabchi, R.Y. Liang, L. Li, H. Liu, Yield acceleration and permanent displacement of a slope reinforced with a row of drilled shafts, Soil Dynamics and Earthquake Engineering 57 (2014) 68-77.

[15] L. Li, R.Y. Liang, Limit equilibrium based design approach for slope stabilization using multiple rows of drilled shafts, Computers and Geotechnics 59 (2014) 67-74.

[16] L. Li, R.Y. Liang, H. Liu, System reliability analysis for anchor-stabilised slopes considering stochastic corrosion of anchors, Structure and Infrastructure Engineering, 2014 [Online], http://dx.doi.org/10.1080/15732479.2014.9636 
26 (accessed Mar. 1, 2014).

[17] L. Li, R.Y. Liang, Reliability based design for slope stabilization using both anchors and drilled shafts, in: Transportation Research Board 93nd Annual Meeting, Washington DC, USA, 2014.

[18] W.H. Tang, M.S. Yucemen, A.H.S. Ang, Probability-based short term design of soil slopes,
Canadian Geotechnical Journal 13 (3) (1976) 201-215.

[19] D.V. Griffiths, G.A. Fenton, Probabilistic slope stability analysis by finite elements, Journal of Geotechnical and Geoenvironmental Engineering 130 (5) (2004) 507-518.

[20] K.K. Phoon, F.H. Kulhawy, Characterization of geotechnical variability, Canadian Geotechnical Journal 36 (1999) 612-624. 